\title{
Influence of circulating $\alpha$ adrenoceptor agonists on lung function in patients with exercise induced asthma and healthy subjects
}

\author{
KJELL LARSSON, ARNE MARTINSSON, PAUL HJEMDAHL \\ From the Department of Thoracic Medicine, Karolinska Hospital; the Department of Clinical Physiology, \\ Södersjukhuset; and the Department of Pharmacology, Karolinska Institute, Stockholm, Sweden
}

\begin{abstract}
The influence of circulating noradrenaline (in this context primarily a non-selective $\alpha$ J agonist) and the $\alpha_{1}$ selective agonist phenylephrine on bronchial tone, blood pressure, and heart rate $ᄋ$ was studied in eight patients with exercise induced asthma and eight age and sex matched controls. All subjects refrained from taking treatment for at least one week before the trial. The agonists were $\subseteq$ infused intravenously in stepwise increasing doses of $0.04,0.085,0.17$, and $0.34 \mu \mathrm{g} / \mathrm{kg}$ a minute for noradrenaline and $0.5,1.0,2.0$, and $4.0 \mu \mathrm{g} / \mathrm{kg}$ a minute for phenylephrine. At the highest dose the plasma concentration of noradrenaline was about $30 \mathrm{nmol} / 1$, resembling the concentrations found during intense exercise, and that of phenylephrine was about $400 \mathrm{nmol} / \mathrm{l}$. Both agonists caused dose dependent and similar increases in blood pressure in the two groups. Despite clearcut cardiovascular effects (systolic and diastolic blood pressure increased by about $40-50 / 25-30 \mathrm{~mm} \mathrm{Hg}$ ), neither agonist altered lung function, as assessed by measurements of specific airway compliance (sGaw), peak expiratory flow (PEF), or end expiratory flow rate, in either group. It is concluded that circulating $\alpha$ agonists, whether $\alpha_{1}$ selective (phenylephrine) or non-selective (noradrenaline), fail to alter basal bronchial tone in patients with exercise induced asthma or in healthy subjects.
\end{abstract}

The role of pulmonary $\alpha$ adrenoceptors in asthma is not clear. Inhaled $\alpha$ agonists have usually caused bronchoconstriction in asthmatic patients but not in healthy subjects, ${ }^{1-3}$ though a small but significant effect has been shown in some healthy subjects. ${ }^{4}$ These in vivo findings are consistent with some in vitro findings that suggest the presence of $\alpha$ adrenoceptor mediated constriction of human airways smooth muscle. ${ }^{5}$ Blockade of $\alpha$ adrenoceptors caused bronchodilatation in one study, ${ }^{6}$ although this finding was not confirmed by others. ${ }^{78}$. Alpha adrenoceptor blocking drugs have also been shown to protect against bronchoconstriction induced by histamine,${ }^{910}$ allergen, ${ }^{11}$ and exercise, ${ }^{12}$ although, again, others have failed to confirm these data. ${ }^{71314}$ Thus the findings with $\alpha$ adrenoceptor agonists and antagonists on the airways of normal subjects and asthmatic patients have not been consistent, though some findings suggest that $\alpha$ adrenoceptor stimulation

Address for reprint requests: Dr Paul Hjemdahl, Department of Pharmacology, Karolinska Institute, Box 60400, S-104 01 Stockholm, Sweden.

Accepted 9 December 1985 might cause bronchoconstriction.

Whether or not the $\alpha$ adrenoceptor sensitivity of asthmatic patients is different from that of controls is $\underset{\times}{\stackrel{D}{\times}}$ also debated. One study has shown greater $\alpha$ adreno- $\dot{\sigma}$ ceptor mediated vascular and pupillary smooth muscle responses in asthmatic patients than in of healthy controls. ${ }^{15}$ Another study, however, showed $₹$ that the $\alpha_{2}$ adrenergic responses of platelets were 의 similar in asthmatic and in healthy subjects. ${ }^{16}$

The aim of the present study was to investigate pul- $\frac{7}{3}$ monary and cardiovascular responses to circulating $\alpha \hat{\bar{N}}$ adrenoceptor agonists in asthmatic patients. We stud- $\sigma$ ied the effect of intravenous phenylephrine (an $\alpha_{1} \hat{\sim}$ selective agonist) and noradrenaline on the airways, N blood pressures, and heart rates of patients with exer- 0 cise induced asthma and matched healthy controls. Circulating noradrenaline acts mainly as a non- $\frac{\mathscr{\Phi}}{\mathscr{C}}$

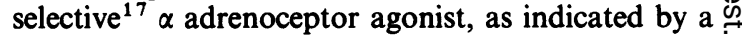
lack of effect of $\beta$ blockade on blood pressure and 0 heart rate responses to infused noradrenaline in $\bar{D}$ man. ${ }^{18}$ Noradrenaline has $\beta_{1}$ stimulating properties, $\stackrel{\mathbb{D}}{\stackrel{D}{ }}$ but this does not cause bronchodilatation in man. ${ }^{19} \stackrel{\mathbb{\mathrm { Q }}}{\mathrm{Q}}$ The effects of $\beta_{1}$ selective and non-selective $\beta$ block- $\frac{\alpha}{\sigma}$ ade on responses to infused noradrenaline are very 
Data on control subjects $(C)$ and patients with excercise induced asthma $(E)$

\begin{tabular}{|c|c|c|c|c|c|c|}
\hline $\begin{array}{l}\text { Subject } \\
\text { No }\end{array}$ & Age (y) & Sex & $\begin{array}{l}\text { Weight } \\
(\boldsymbol{k g})\end{array}$ & $\begin{array}{l}\text { Height } \\
(\mathrm{cm})\end{array}$ & $\begin{array}{l}\text { Basal PEF } \\
\left(l s^{-1}\right)\end{array}$ & Treatment ${ }^{*}$ \\
\hline $\begin{array}{l}\mathrm{C} 1 \\
\mathrm{C} 2 \\
\mathrm{C} 3 \\
\mathrm{C} 4 \\
\mathrm{C} 5 \\
\mathrm{C} 6 \\
\mathrm{C} \\
\mathrm{C} 8\end{array}$ & $\begin{array}{l}25 \\
28 \\
16 \\
22 \\
32 \\
29 \\
31 \\
23\end{array}$ & $\begin{array}{l}\mathbf{M} \\
\mathbf{M} \\
\mathbf{M} \\
\mathbf{M} \\
\mathbf{F} \\
\mathbf{M} \\
\mathbf{M} \\
\mathbf{M}\end{array}$ & $\begin{array}{l}83 \\
74 \\
72 \\
66 \\
56 \\
73 \\
70 \\
62\end{array}$ & $\begin{array}{l}173 \\
186 \\
182 \\
169 \\
175 \\
185 \\
175 \\
184\end{array}$ & $\begin{array}{r}8.98 \\
7.67 \\
7.77 \\
9.14 \\
7.30 \\
8.03 \\
11.08 \\
8.40\end{array}$ & $\begin{array}{l}- \\
- \\
- \\
- \\
-\end{array}$ \\
\hline $\begin{array}{l}\text { E1 } \\
\text { E2 } \\
\text { E4 }\end{array}$ & $\begin{array}{l}25 \\
27 \\
17 \\
19\end{array}$ & $\begin{array}{l}\mathbf{M} \\
\mathbf{M} \\
\mathbf{M} \\
\mathbf{M}\end{array}$ & $\begin{array}{l}85 \\
86 \\
74 \\
65\end{array}$ & $\begin{array}{l}185 \\
180 \\
179 \\
169\end{array}$ & $\begin{array}{r}10.60 \\
6.93 \\
6.10 \\
5.78\end{array}$ & $\begin{array}{l}\text { Terbutaline (MDI) } \\
\text { Terbutaline (MDI) } \\
\text { Salbutamol (MDI) } \\
\text { SCG (spinhaler); terbutaline } \\
\quad \text { (tablets) } 2.5 \mathrm{mg} \text { seasonally } \\
\quad \text { twice daily }\end{array}$ \\
\hline $\begin{array}{l}\text { E5 } \\
\text { E6 }\end{array}$ & $\begin{array}{l}33 \\
28\end{array}$ & $\begin{array}{l}\mathbf{F} \\
\mathbf{M}\end{array}$ & $\begin{array}{l}53 \\
70\end{array}$ & $\begin{array}{l}159 \\
175\end{array}$ & $\begin{array}{l}5.25 \\
7.51\end{array}$ & $\begin{array}{c}\text { Terbutaline (MDI) } \\
\text { Terbutaline (MDI); } \\
\text { SCG (spinhaler) }\end{array}$ \\
\hline E7 & 36 & $\mathbf{M}$ & 94 & 183 & 8.61 & $\begin{array}{l}\text { Choline theophyllinate } \\
\text { (tablets) } 135 \mathrm{mg}\end{array}$ \\
\hline E8 & 24 & $\mathbf{M}$ & 83 & 188 & 10.08 & Terbutaline (MDI) \\
\hline
\end{tabular}

*As needed, unless otherwise specified.

MDI-metered dose inhalers; SCG-sodium cromoglycate.

similar in man. ${ }^{18}$ Thus noradrenaline may be regarded as a non-selective $\alpha$ adrenoceptor agonist in this context. Patients with exercise induced asthma were studied since they develop asthma after physical exertion, when circulating noradrenaline concentrations are increased. In the present study the responses were related to the plasma concentrations rather than to the infused doses of phenylephrine and noradrenaline.

\section{Methods}

\section{SUBJECTS}

Eight patients with exercise induced asthma and eight age and sex matched healthy control subjects were studied (table). Exercise induced asthma was confirmed by demonstrating a fall in $\mathrm{FEV}_{1}$ of greater than $15 \%$ in a pretrial exercise test on a treadmill. All subjects were non-smokers and took no treatment for at least one week before the trial. The subjects gave their informed consent to participate in the study, which had been approved by the local ethical committee.

\section{MEASUREMENTS}

Blood pressure was measured non-invasively with an Automanometer (Electronic Research and Development, Dunedin, New Zealand), which allows measurements to be made blind. ${ }^{20}$ Heart rate was monitored by telemetry. Lung volumes, airway resistance, and indirectly specific airway conductance (sGaw) were measured in a constant volume body plethysmograph (PK Morgan Ltd, Chatham, UK), from which flow-volume loops were also recorded. Airway resistance was measured at a panting frequency of about two per second and a flow rate of about $0.51 \mathrm{~s}^{-1}$. Functional residual capacity and $\mathrm{sGaw}$ were determined as the mean of three measurements. When appropriate, two flow-volume loops (with a difference in PEF of less than 10\%) were recorded and the peak flow rate and maximum expiratory flow rates at $50 \%$ $\left(\mathrm{MEF}_{50}\right)$ and $25 \%\left(\mathrm{MEF}_{25}\right)$ of forced vital capacity (FVC) were calculated from the loop with the highest PEF. The mean slope of the flow-volume curve between $50 \%$ and $25 \%$ of FVC (FEF $50-25)$ was calculated according to the equation

$$
\frac{4\left(\mathrm{MEF}_{50}-\mathrm{MEF}_{25}\right)}{\text { FVC }}
$$

All lung function measurements were carried out in the following order: airway resistance, lung volumes, and finally the iow-volume loops. Infusions were given with a Perfusor ED2 pump (B Braun, Melsungen, West Germany) equipped with an accumulator to allow continuous infusions in the closed body plethysmograph.

Catecholamines were analysed according to Hjemdahl et al. ${ }^{2122}$ In our laboratory the method has a sensitivity better than $0.05 \mathrm{nmol} / 1$ for all three catecholamines (adrenaline, noradrenaline, and dopamine) and has interassay and intra-assay coefficients of variation of about $10 \%$ in the $0.1-0.2 \mathrm{nmol} / 1 \mathrm{con}$ centration range and $2-3 \%$ above $1-2 \mathrm{nmol} / \mathrm{l}$. A brief description of the phenylephine assay has been given. ${ }^{23}$ The full details of the assay are to be published later. In essence, $2 \mathrm{ml}$ of plasma (with orciprenaline $400 \mathrm{pmol}$ added as internal standard) was deproteinised by the addition of $220 \mu \mathrm{l} 3 \mathrm{~mol} / 1$ perchloric acid. After centrifugation at $15000-20000$ 
$g$ for 20 minutes at $4^{\circ} \mathrm{C}$ the supernatant was collected and mixed with $2 \mathrm{ml} 800 \mathrm{mmol} / \mathrm{l}$ boric acid and $80 \mu \mathrm{mol} / 1 \mathrm{EDTA}$ in $1 \mathrm{~mol} / 1 \mathrm{NaOH}$. The sample was passed through a Sep Pak $\mathrm{C}_{18}$ column (Waters Associates). After the column had been washed with distilled water, phenylephrine and orciprenaline were eluted in $5 \mathrm{ml} 0.1 \mathrm{~mol} / 1$ acetic acid and $0.1 \mathrm{mmol} / 1$ sodium metabisulphite with $10 \%$ methanol. After concentration by lyophilisation the samples were finally suspended in $0.1 \mathrm{~mol} / 1$ perchloric acid containing $0.1 \mathrm{mmol} / \mathrm{l}$ sodium metabisulphite. Liquots of 50-100 $\mu$ l were analysed by high pressure liquid chromatography with a strong cation exchange column (Nucleosil 10SA, $30 \mathrm{~cm}$ ) and electrochemical detection. The oxidating potential was $+0.95 \mathrm{v}$. The interassay and intra-assay coefficients of variation for the analysis were $10.6 \%$ and $19.1 \%$ at $20 \mathrm{nmol} / 1$ of phenylephrine and $6.5 \%$ and $7.1 \%$ at $200 \mathrm{nmol} / \mathrm{l}$. Recovery was $50-60 \%$ for phenylephrine and $60-70 \%$ for orciprenaline over a large number of determinations. This allowed a correction factor for recovery to be introduced into the calculations.

\section{PROCEDURE}

Venous cannulas were inserted into an antecubital vein on each arm (one for sampling and one for infusion) and electrocardiograph electrodes (three leads) and blood pressure cuff were applied. The subjects then rested in the supine position for 20 minutes, which was followed by 10 minutes' rest in the seated position in the body plethysmograph. Basal blood pressures and heart rate were recorded and a $10 \mathrm{ml}$ blood sample was drawn. After two basal measurements (five minutes apart) lung function measurements were performed. Noradrenaline was subsequently infused at four dose rates, increasing stepwise $(0.04,0.085,0.17$, and $0.34 \mu \mathrm{g} / \mathrm{kg}$ a minute), each step being maintained for eight minutes. Blood pressure was recorded each minute for the first five minutes and at eight minutes. The heart rate was monitored continuously. Venous blood samples were drawn four and eight minutes after the start of the infusion and lung function tests were repeated during the last three minutes.

After the noradrenaline infusion subjects rested for two hours. Repeated basal measurements were performed as in the first study and followed by an infusion of phenylephrine at four dose rates $(0.5,1.0$, 2.0 , and $4.0 \mu \mathrm{g} / \mathrm{kg}$ a minute), each dose rate being maintained for six minutes. Blood pressure and heart rate were recorded each minute and venous blood samples drawn during the last minute. After six minutes the infusion was stopped and lung function tests were repeated. When these had been performed after the highest dose of phenylephrine, $5 \mathrm{mg}$ of salbutamol was inhaled and final lung function tests were performed 10 minutes later. Lung function, blood pressure, and heart rate were related to the phenylephrine concentration six minutes after the start of the infusion.

\section{STATISTICAL ANALYSIS}

All results are presented as mean values with standard errors in parentheses. Student's $t$ tests for paired or unpaired variates and linear regression analyses were used. A p value of $<0.05$ was considered significant. The coefficient of variation for sGaw measurements was $12 \%$. When sGaw measurements were repeated in 13 healthy subjects on the same day the second
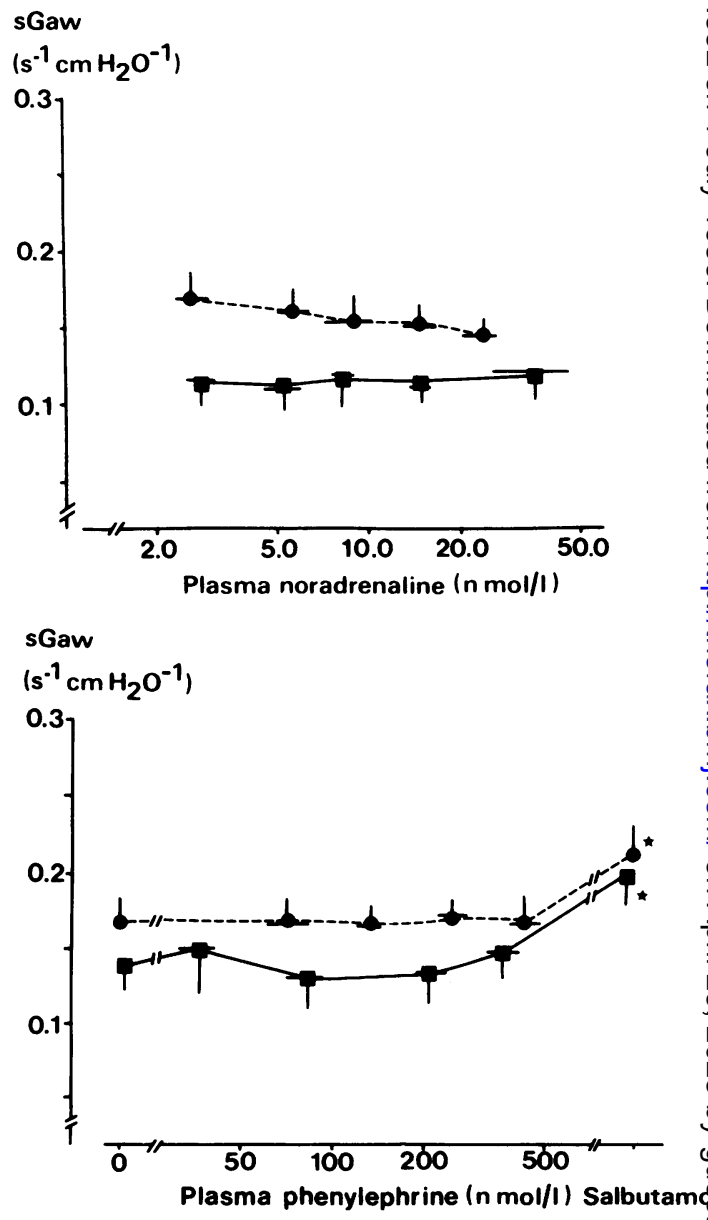

Fig 1 Effects of increasing plasma concentrations of noradrenaline and phenylephrine on specific airway conductance (sGaw) in control subjects (-- $\bullet$ ) and in patients with exercise induced asthma ( -0$)$. The post-salbutamol values were significantly higher than the basal values obtained before the noradrenaline infusion. Bars indicate standard errors. ${ }^{*} p<0.05$. 

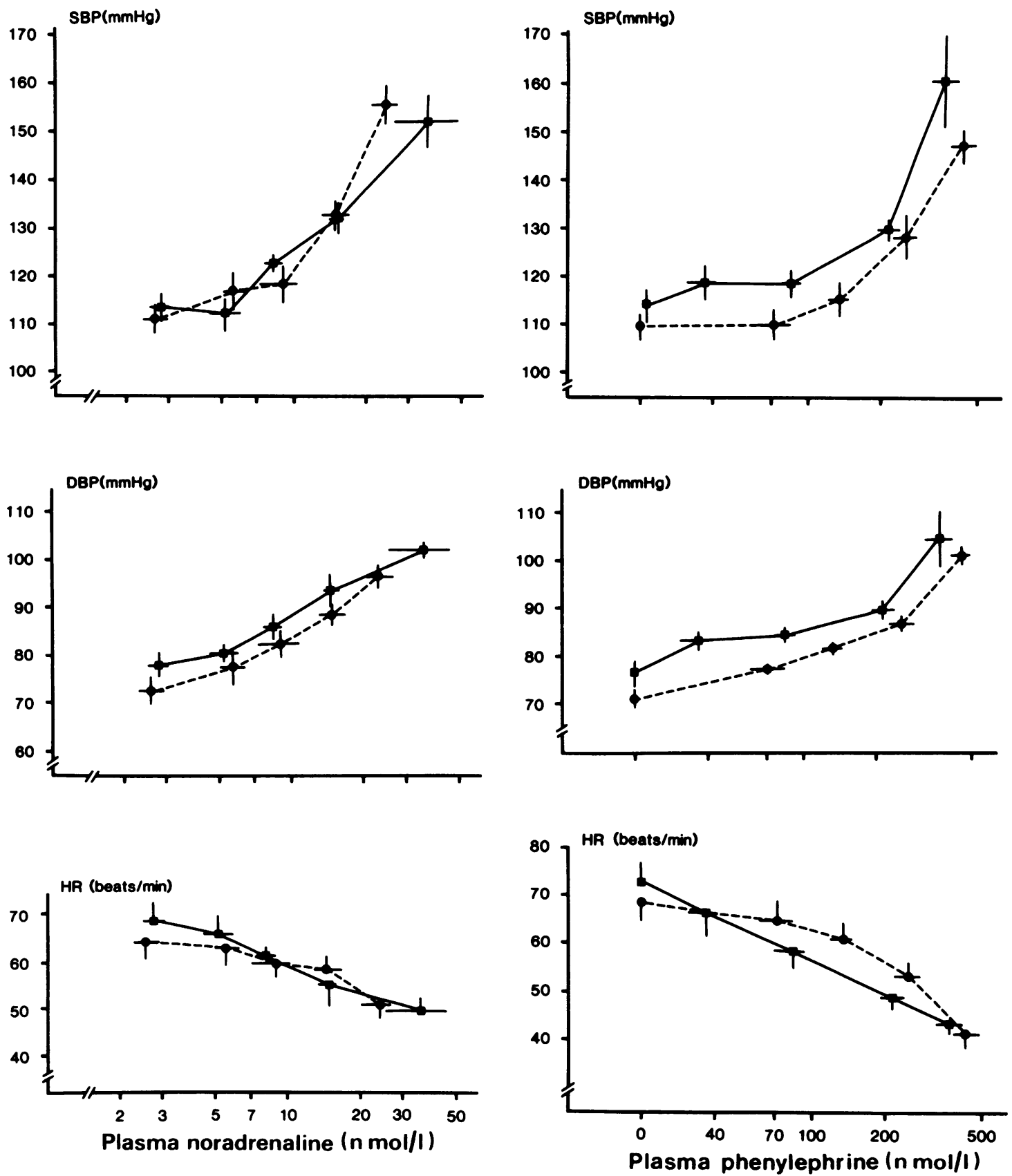

Fig 2 Heart rate (HR), systolic blood pressure (SBP), and diastolic blood pressure (DBP) in control subjects (--- $\bullet$ ) and patients with exercise induced asthma (_) in relation to the venous plasma noradrenaline concentrations determined before infusion and after eight minutes of infusions at each dose rate. All indices were significantly different from basal values in both groups at the second or third dose rate.

Fig 3 Effects of increasing plasma concentrations of phenylephrine on systolic blood pressure (SBP), diastolic blood pressure (DBP), and heart rate $(H R)$. All three indices were significantly different from basal values at the first or second dose rate in both groups. --- control subjects; $\square$ patients with exercise induced asthma. 
measurement was $1.6 \%(3.4 \%)$ higher than the first (a non-significant difference), suggesting that if the patients behaved in a similar way the probability of detecting a mean decrease in sGaw of more than $15 \%$ in the present study was greater than $\mathbf{9 0 \%}$.

\section{Results}

All subjects had a baseline PEF of $68 \%$ or more of their predicted normal value. In the asthmatic group mean basal sGaw before phenylephrine infusion was slightly higher than basal values before noradrenaline $\left(0.139(0.022)\right.$ compared with $0.116(0.016) \mathrm{s}^{-1} \mathrm{~cm}$ $\mathrm{H}_{2} \mathrm{O}^{-1} ; \mathrm{p}<0.05$ ). None of the other basal lung function measurements differed significantly.

The asthmatic patients had significantly lower basal $\mathrm{MEF}_{50}$ before noradrenaline than the control subjects $\left(3.19(0.30) v 4.40(0.35) 1 \mathrm{~s}^{-1} ; \mathrm{p}<0.05\right)$ and adrenaline infusions $\left(3.26(0.33) v 4.51(0.35) 1 \mathrm{~s}^{-1} ; \mathrm{p}\right.$ $<0.05$ ). Basal sGaw was significantly lower in the asthmatic patients than in the controls before nor$\begin{array}{llllll}\text { adrenaline }(0.116 & (0.016) & v & 0.17 & (0.016) \mathrm{s}^{-1} \mathrm{~cm}\end{array}$ $\left.\mathrm{H}_{2} \mathrm{O}^{-1} ; \mathrm{p}<0.05\right)$, but not phenylephrine $(0.139$ (0.022) v $\left.0.168(0.016) \mathrm{s}^{-1} \mathrm{~cm} \mathrm{H}_{2} \mathrm{O}^{-1}\right)$. Basal PEF and $\mathrm{FEF}_{50-25}$ showed no significant differences between the two groups.

The plasma concentrations of noradrenaline increased from basal levels of $2.79(0.25) \mathrm{nmol} / \mathrm{l}$ in the asthmatic paitients and $2.63(0.31) \mathrm{nmol} / 1$ in control subjects to $35.5(10.5) \mathrm{nmol} / \mathrm{l}$ and $24.2(2.6) \mathrm{nmol}$, respectively, after eight minutes of infusion at the highest noradrenaline dose rate. Similar values were present after four minutes of infusion. Infusion of phenylephrine yielded maximum plasma concentrations of $364(52) \mathrm{nmol} / \mathrm{l}$ in the asthmatic patients and $446(48) \mathrm{nmol} / \mathrm{l}$ in the controls. Hence at the highest doses venous plasma concentrations of noradrenaline were about $50 \%$ higher and those of phenylephrine about $20 \%$ lower in the asthmatic patients than in control subjects. During noradrenaline or phenylephrine infusion there was no significant change in lung volumes (FRC and FVC), sGaw, or expiratory flow rates $\left(\mathrm{PEF}, \mathrm{MEF}_{50}, \mathrm{MEF}_{25}\right.$ and $\left.\mathrm{FEF}_{50-25}\right)$ in either group. Inhalation of salbutamol caused a significant percentage increase in mean sGaw in both control and asthmatic subjects (25 (9) and 90 (29): fig 1); but the percentage increases in PEF (2.8 (2.7) and 9.2 (1.7) and MEF 50 (13.0 (4.5) and 26.5 (4.6) in response to salbutamol achieved significance only in the asthmatic patients.

Blood pressure and heart rate before the infusions did not differ significantly between normal and asthmatic subjects. Systolic and diastolic blood pressure increased and heart rate decreased with increasing doses of both $\alpha$ agonists in normal and asthmatic subjects (figs 2 and 3). There was no significant difference between the groups in the blood pressure response and no correlation between basal heart rate and the decrease in heart rate induced by noradrenaline or phenylephrine in either group. Decreases in heart rate correlated closely with increases in systolic and diastolic blood pressure during both infusions in both groups ( $\mathrm{p}<0.01-0.001)$.

\section{Discussion}

The patients considered themselves to be free from asthmatic symptoms at the time of the study despite a treatment free interval of at least one week before the trial. This was confirmed by high basal PEF values, which were not significantly different from the values of the control group. Nevertheless, more sensitive indicators of larger airways (sGaw) and smaller airways function (end expiratory flow rates) showed slight bronchial constriction in the asthmatic subjects before the study.

In the present study neither circulating noradrenaline, in this context primarily a non-selective $\alpha \stackrel{\mathscr{O}}{\mathscr{Q}}$ agonist, nor phenylephrine, an $\alpha_{1}$ selective agonist, influenced airway function. The plasma concentrations of noradrenaline obtained during these infusions were as high as those seen during heavy exercise ${ }^{24}$ which is the specific stimulus inducing exercise induced asthma. Appreciat.le changes in $\varnothing$ heart rate and blood pressure were also observed. $\overrightarrow{\overrightarrow{0}}$ Phenylephrine was administered in doses that 3 induced similar cardiovascular responses to those of heavy exercise. Physiologically relevant concentrations of circulating $\alpha$ adrenoceptor agonists do not seem to influence bronchial tone in either patients with exercise induced asthma or controls. The present results do not support the idea ${ }^{2526}$ that high plasma noradrenaline concentrations in connection with exercise are of pathophysiological importance in exercise induced asthma.

Even though we found no bronchial response to 9 circulating $\alpha$ agonists, $\alpha$ adrenoceptors probably do $\supset$ exist in human airways. ${ }^{15}$ Stimulation of these receptors by inhalation of $\alpha_{1}$ agonists, such as meth- $N$ oxamine and phenylephrine, has been shown to induce bronchoconstriction. ${ }^{1-4}$ Alpha adrenoceptor $\tilde{O}$ antagonists given systemically are capable of preventing asthma induced by histamine ${ }^{910}$ and $O$ allergen $^{11}$. Results obtained with alpha blockers may, 0 however, be related to additional pharmacological properties of these drugs, such as inhibition of hista- $\stackrel{?}{+}$ mine or serotonin or direct actions on the smooth 0 muscle, ${ }^{27}$ rather than blockade of $\alpha$ adrenoceptors.

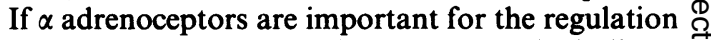
of bronchial tone in man, the present results indicate $\stackrel{\mathbb{Q}}{\mathbb{2}}$ that they should be activated by locally released noradrenaline. It is not yet clear whether $\alpha$ adrenoceptors 
of the human airways are innervated by sympathetic nerves. In dogs $\alpha$ mediated bronchoconstriction in vitro occurs mainly through stimulation of $\alpha_{2}$ adrenoceptors, which seem to be innervated. ${ }^{28}$ Although the lungs seem to release noradrenaline into plasma, ${ }^{29}$ previous efforts to demonstrate sympathetic innervation of the human bronchial smooth muscle have failed. ${ }^{30}{ }^{31}$ Recent findings suggest that there is a sparse adrenergic innervation of bronchial smooth muscle in man, ${ }^{32} 33$ in addition to the rich sympathetic innervation of pulmonary blood vessels $^{3133}$ and submucosal glands. ${ }^{32}$ The latter nerves are probably the most important source of noradrenaline released from the lungs into the circulation. A spillover effect from nerve endings not directly innervating the bronchial smooth muscle could, however, also result in high noradrenaline concentrations in the vicinity of bronchial smooth muscle in vivo without an extensive direct innervation of the broncial smooth muscle. Since the influence of locally released noradrenaline on human broncial smooth muscle tone in vivo has not been examined, the role of $\alpha$ adrenoceptors in the human airways is still unclear.

All subjects were normotensive and the basal preinfusion blood pressures were similar in the two groups. Noradrenaline and phenylephrine evoked clearcut increases in blood pressure and those responses were similar in the two groups. A previous study of cutaneous blood flow and pupillary responses to phenylephrine provided evidence supporting increased $\alpha$ adrenergic responsiveness in patients with allergic asthma. ${ }^{15}$ Although blood pressure is controlled by more complex mechanisms, our results suggest that vascular $\alpha$ adrenoceptor sensitivity was normal in the patients with exercise induced asthma.

In conclusion, we found no alteration of basal bronchial tone during intravenous infusions of $\alpha_{1}$ selective (phenylephrine) or non-selective (noradrenaline) $\alpha$ adrenoceptor agonists in patients with exercise induced asthma and no indication of an increased vascular $\alpha$ adrenoceptor sensitivity in these asthmatic patients. Circulating noradrenaline does not seem to be of pathophysiological importance in the development of postexercise bronchoconstriction in exercise induced asthma.

This study was supported by grants from the Swedish National Association Against Heart and Chest Diseases, the Swedish Medical Research Council (5930), the Karolinska Institute, and the Swedish Society of Medicine. We sincerely thank Assistant Professor Sture Bevegård for access to his laboratory facilities. We gratefully acknowledge the expert laboratory assistance of Caroline Angleryd, Maud Daleskog, Maj-Christina Johansson, and Berith Nilsson, and the secretarial assistance of Monica Häggbom.

\section{References}

1 Simonsson BG, Svedmyr N, Skoogh B-E, Andersson R, Bergh NP. In vivo and in vitro studies on alpha-receptors in human airways. Potentiation with bacterial endotoxin. Scand J Respir Dis 1972;53:227-36.

2 Snashall PD, Boother FA, Sterling GM. The effect of $\alpha$-adrenoceptor stimulation on the airways of normal and asthmatic man. Clin Sci Mol Med 1978;54:283-9.

3 Black JL, Salome CM, Yan K, Shaw J. Comparison between airways response to an $\alpha$-adrenoceptor agonist and histamine in asthmatic and non-asthmatic subjects. Br J Clin Pharmacol 1982;14:464-6.

4 Anthracite RF, Vachon L, Knapp PH. Alpha-adrenergic receptors in the human lung. Psychosom Med 1971; 33:481-9.

5 Kneussl MP, Richardson JB. Alpha-adrenergic receptors in human and canine tracheal and bronchial smooth muscle. J Appl Physiol 1978;45:307-11.

6 Campbell SC. Effects of alpha-adrenergic blockade with phentolamine on airway function in asthma. Ann Allergy 1982;49:135-8.

7 Löllgen H, Nieding GV, Löllgen-Horres I. Effect of an $\alpha$-adrenergic-blocking drug on bronchodilatation and protection in provocation tests in patients with chronic obstructive airways disease, bronchial asthma and in non-responders. Respiration 1977;34:314-22.

8 Barnes PJ, Ind PW, Dollery CT. Inhaled prazosin in asthma. Thorax 1981;36:378-81.

9 Gaddie J, Legge JS, Petrie G, Palmer KNV. The effect of an alpha-adrenergic receptor blocking drug on histamine sensitivity in bronchial asthma. Br J Dis Chest 1972; 66:141-6.

10 Kerr JW, Govindaraj M, Patel KR. Effect of alphareceptor blocking drugs and disodium cromoglycate on histamine hypersensitivity in bronchial asthma. Br Med J 1970;ii:139-41.

11 Patel KR, Kerr JW. Effect of alpha receptor blocking drug, thymoxamine on allergen induced bronchoconstriction in extrinsic asthma. Clin Allergy 1975; 5:311-6.

12 Barnes PJ, Wilson NM, Vickers H. Prazosin, an alpha $_{1}$-adrenoceptor antagonist, partially inhibits exercise-induced asthma. J Allergy Clin Immunol 1981;68:411-5.

13 Pegelow K-O. Bronchial reactivity to inhaled histamine in asthmatic patients before and after administration of atropine, phentolamine or disodium cromoglycate. Acta Allergol 1974;29:365-84.

14 Sly RM, Heimlich EM, Busser RJ, Strick L. Exerciseinduced bronchospasm: effects of adrenergic or cholinergic blockade. J Allergy 1967;40:93-9.

15 Henderson WR, Shelhamer JH, Reingold DB, Smith LJ, Evans R, Kaliner M. Alpha-adrenergic hyperresponsiveness in asthma. Analysis of vascular and pupillary responses. $N$ Engl J Med 1979;300:642-7.

16 Davis PB, Lieberman P. Normal alpha 2 -adrenergic responses in platelets from patients with asthma. $J$ Allergy Clin Immunol 1982;69:35-8.

17 Fain JN, Garcia-Sainz JA. Role of phosphatidylinositol turnover in alpha $1_{1}$ and of adenylate cyclase inhibition in alpha $_{2}$ effects of catecholamines. Life Sci 1980; 26:1183-94.

18 Hjemdahl P, Åkerstedt T, Pollare T, Gillberg M. Influence of $\beta$-adrenoceptor blockade by metoprolol and propranolol on plasma concentrations and effects of noradrenaline and adrenaline during i.v. infusion. Acta 
Physiol Scand 1983;suppl 515:45-53.

19 Löfdahl CG, Svedmyr N. Effects of prenalterol in asthmatic patients. Eur J Clin Pharmacol 1982;23:297-302.

20 Nyberg G. Indirect blood pressure and heart rate measured quickly without observer bias using a semiautomatic machine (auto-manometer) response to isometric exercise in normal healthy males and its modification by $\beta$-adrenoceptor blockade. $\mathrm{Br} J \mathrm{Clin}$ Pharmacol 1977;4:275-81.

21 Hjemdahl P, Daleskog M, Kahan T. Determination of plasma catecholamines by high performance liquid chromatography with electrochemical detection: comparison with radioenzymatic method. Life Sci 1979;25:131-8.

22 Hjemdahl P. Catecholamine measurements by high performance liquid chromatography. Am J Physiol 1984; 247:E13-20.

23 Martinsson A, Hjemdahl P, Carlens P, Bevegård S. Determination of phenylephrine in plasma and its relationship to the blood pressure response during i.v. infusion. In: Proceedings of 2nd World Conference on Clinical Pharmacology and Therepeutics. Washington, 1983:327.

24 Cryer PE. Physiology and pathophysiology of the human sympathoadrenal neuroendocrine system. $N$ Engl $J$ Med 1980;303:436-44.

25 Reinhardt D, Nagel M, Stemmann EA, Wegner F. Catecholamines and cyclic AMP in allergic and exercise induced asthma of childhood. Eur J Pediatr 1980; 134:45-50.
26 Zielinski J, Chodosowska E, Radomyski A, Araszkiewicz Z, Kozlowski S. Plasma catecholamines during exercise-induced bronchoconstriction in bronchial asthma. Thorax 1980;35:823-7.

27 Bowman WC, Rand MJ. $\alpha$-Receptor antagonists. In: Bowman WC, Rand MJ. Textbook of pharmacology. 2nd Ed. Oxford: Blackwell Scientific Publications, 1980:11.40-5.

28 Barnes PJ, Skoogh B-E, Nadel JA, Roberts JM. Post- ڤ synaptic alpha ${ }_{2}$-adrenoceptors predominate over $\vec{O}$ alpha ${ }_{1}$-adrenoceptors in canine tracheal smooth muscle and mediate neuronal and hormonal alpha-adrenergic contraction. Mol Pharmacol 1983;23:570-5.

29 Esler M, Jennings G, Leonard P, et al. Contribution of individual organs to total noradrenaline release in ? humans. Acta Physiol Scand 1984;suppl 527:11-6.

30 Richardson J, Beland J. Nonadrenergic inhibitory ner- $V$ vous system in human airways. $J$ Appl Physiol if 1976;41:764-71.

31 Doidge JM, Satchell DG. Adrenergic and nonadrenergic inhibitory nerves in mammalian airways. Journal of the Autonomic Nervous System 1982;5:83-99. $\vec{c}$

32 Pack RJ, Richardson PS. The aminergic innervation of the human bronchus: a light and electron microscopic study. J Anat 1984;138:493-502.

33 Partanen M, Laitinen A, Hervonen A, Toivanen M, Laitinen LA. Catecholamine- and acetylcholinesterasecontaining nerves in human lower respiratory tract. Histochemistry 1982;76:175-88. 